\title{
GREEN SYNTHESIS OF CALCIUM CARBONATE WITH UNUSUAL MORPHOLOGIES IN THE PRESENCE OF FRUIT EXTRACTS
}

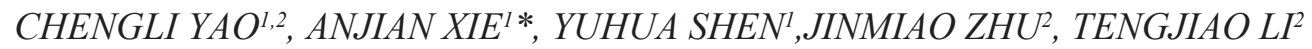

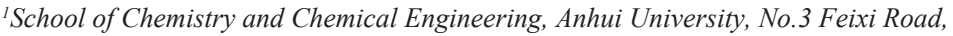 \\ Hefei,Anhui ,230039,PR China \\ ${ }^{2}$ Department of Chemistry and Chemical Engineering, Hefei Normal University, No. 1688 Lianhua Road,Hefei, Anhui, 230601,PR China
}

(Received: May 6, 2013 - Accepted: June 27, 2013)

\begin{abstract}
In the present investigation, we reported a novel green strategy for the biological synthesis of calcium carbonate crystals using water-soluble polysaccharides extracted from the apple and pear. The resultant crystals were characterized by scanning electron microscopy (SEM), Fourier transform infrared (FT-IR) spectroscopy, and X-ray powder diffractometry (XRD). The results showed that water-soluble polysaccharides as a soft template were easy to induce calcium carbonate with unusual morphologies (such as straw bundles-like). Based on the time-dependent growth of $\mathrm{CaCO}_{3}$ particles, possible mechanisms were proposed for the formation of straw bundle-like $\mathrm{CaCO}_{3}$ microspheres with secondary structures in the presence of water-soluble polysaccharides.
\end{abstract}

Keywords: Water-soluble Polysaccharides, Calcium Carbonate, Biomineralization, Green synthesis, Biomimetic synthesis

\section{INTRODUCTION}

Biomineralization is a widespread phenomenon in nature, under mild conditions, producing inorganic-organic hybrid biominerals. These biominerals are produced by self-assembled bottom up processes, and showed interesting properties with controlled hierarchical structures. According to previous literatures, it is not difficult to find many biological molecules used as templates to induce biomineralization. For example, protein, DNA, polymer, biomolecules and polysaccharide were widely used to induce the formation of calcium salts. Polysaccharides are mainly hydroxylated, carboxylated, sulfated or contain a mixture of these functional moieties ${ }^{1-6}$. Polysaccharides from various sources recently emerged as an important class of bioactive substances. Some polysaccharides have been used as important components of therapeutic drugs and skin care products ${ }^{7-9}$. Since Abolins-Krogis' work ${ }^{10}$, there was an increasing interest which had been developed to explore the role of polysaccharides in biomineralization. Alginate and chitosan are both natural polysaccharides. Alginate and chitosan were frequently employed as a substrate to mimic biomineralization ${ }^{11-16}$. The extracted polysaccharides were also used to mimic biomineralization as matrix. $\mathrm{CaCO}_{3}$ crystals were synthesized by different carrageenans with the unique morphology and uniform size ${ }^{17}$. Coccolith polysaccharides ${ }^{18}$ could elongate the calcite crystal along $\mathrm{c}$-axis and induce the formation of tabular calcite crystal in the agarose gel. Exopolysaccharides and capsular polysaccharides ${ }^{19}$ were able to influence the resulting morphology of $\mathrm{CaCO}_{3}$ in vitro. Multilayer hollow microcapsules were fabricated by layer-by-layer assembly of natural polysaccharides onto $\mathrm{CaCO}_{3}$ particles with core removal ${ }^{20}$. Polysaccharides, such as, beta-cyclodextrin, hepatin, dextrans and soluble starch caused inhibition of the overall calcium carbonate precipitation process ${ }^{21-23}$. Also, variation in crystal morphology was possible, even with only a few polysaccharide side chains, since it was clear that the effects of inhibition were considerably different, depending on the saccharide units chosen to make up the polymer ${ }^{24}$.

Most of the above polysaccharides were extracted or modificated by chemical methods. This method is not consistent with the concept of green chemistry. The current trend of "green chemistry" depends on the eco-friendly technique for the production of well-characterized particles. The validity of the synthesis of "green" particles depends on the nature of the solvent, couple with minimal wastage in terms of energy and raw materials, safety in material synthesis and reducing impact on the environment. In the experiment, polysaccharides were extracted from apple and pear only by boiling deionized water. Here,we present the results of precipitation experiments of $\mathrm{CaCO}_{3}$ under the influence of polysaccharides.

\section{EXPERIMENTAL}

Preparation of soluble polysaccharides

The preparation of soluble polysaccharides was according to the previously described ${ }^{25-27}$. Apple and pear were purchased from a local commercial market.
The apple and pear were cleaned and then cut into pieces. $200 \mathrm{~g}$ of twice washed ripened apple pieces or pear pieces was boiled in $250 \mathrm{~mL}$ deionized water for $30 \mathrm{~min}$, cooled to room temperature and filtered. Filtering was always carried out through four-fold muslin cloth, and centrifuged (centrifugating rate, $4000 \mathrm{r} / \mathrm{min}$ ). The clarifying solution was collected and the residues were subjected to the above extraction for two times. The final concentration of fruit extracts (polysaccharides extracted from apple, named as AP; polysaccharides extracted from pear, named as $\mathbf{P P}$ ) aqueous solution was adjusted to about 5 $\mathrm{mg} / \mathrm{mL}$. All solutions were prepared from freshly boiled deionized water.

Preparation of $\mathrm{CaCO}_{3}$ crystals

All chemicals - calcium chloride, and sodium carbonate-were of analytical grade and were used without further purification. The crystallization of $\mathrm{CaCO}_{3}$ was carried out in a desiccator at room temperature $\left(22 \pm 3^{\circ} \mathrm{C}\right)$. In a typical run, a solution (A) of $\mathrm{Na}_{2} \mathrm{CO}_{3}(50 \mathrm{mM})$ and a mixture solution (B) containing soluble polysaccharide (AP $2.5 \mathrm{mg} / \mathrm{mL}, \mathrm{AP} 1.25 \mathrm{mg} / \mathrm{mL}, \mathrm{PP} 2.5 \mathrm{mg}$ / $\mathrm{mL}$, PP $1.25 \mathrm{mg} / \mathrm{mL}$, respectively) and $\mathrm{CaCl}_{2}(50 \mathrm{mM})$ were prepared by using doubly distilled water. After solution $\mathrm{B}(100 \mathrm{~mL})$ was injected into a glass bottle $(500 \mathrm{~mL})$ and stirred for $30 \mathrm{~min}$. Subsequently, $100 \mathrm{~mL}$ solution (A) was added to the bottle. The system was stirred for $30 \mathrm{~min}$ again. The white precipitates were produced in the reaction solutions containing fruit extracts which were separated by centrifugation (centrifugating rate, $4000 \mathrm{r} / \mathrm{min}$ ), washed three times with double-distilled water and ethanol, respectively, and then vacuum dried for further determination(Scheme 1) .

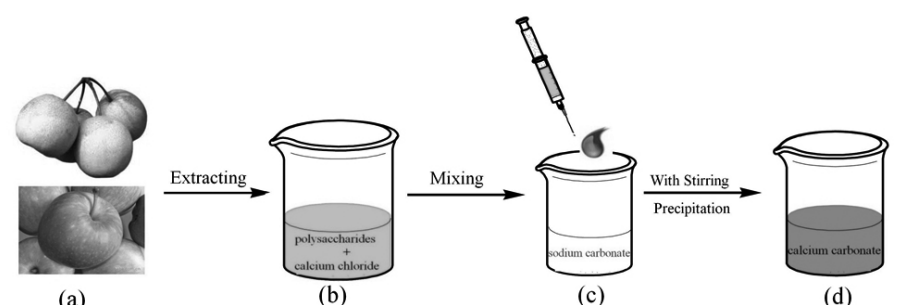

Scheme 1: Schematic representation for the synthesis of calcium carbonate.

\section{Characterization}

The morphologies of the calcium carbonate crystals were characterized by scanning electron microscopy (SEM, S-4800) after being sputter-coated with a thin layer of gold nanoparticles. While their crystalline phases and components were determined by X-ray powder diffraction (XRD, MAP18XAHF) and fourier transform infrared (FTIR, Nexus 870). Thermogravimetric analysis (TGA) was performed with a TGAQ5000 (TA Instruments) to monitor the weight loss of the samples at a heating rate of $10{ }^{\circ} \mathrm{C} / \mathrm{min}$ from room temperature to $900^{\circ} \mathrm{C}$ under a nitrogen atmosphere. Some apple polysaccharides were collected and lyophilized, also measured by Fourier transform infrared (FTIR, Nexus 870). 


\section{RESULTS AND DISCUSSION}
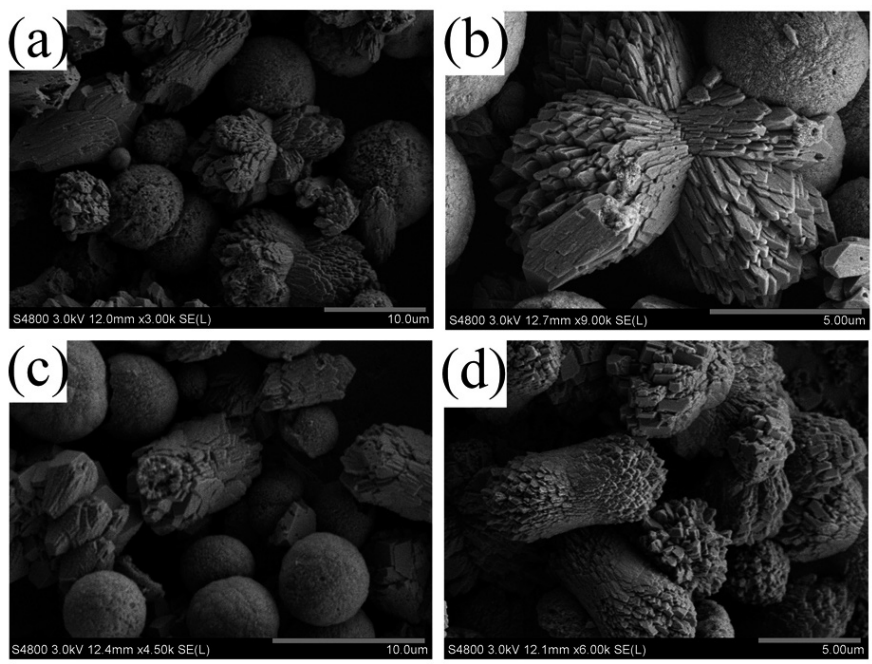

Figure 1. SEM images of the samples obtained at various concentrations of polysaccharide after $24 \mathrm{~h}$ of reaction: (a) $\operatorname{PP}(1.25 \mathrm{mg} / \mathrm{mL})$, (b) $\operatorname{PP}(2.5 \mathrm{mg}$ / $\mathrm{mL}),(\mathrm{c}) \mathrm{AP}(1.25 \mathrm{mg} / \mathrm{mL})$ and (d) $\mathrm{AP}(2.5 \mathrm{mg} / \mathrm{mL})$

SEM images of $\mathrm{CaCO}_{3}$ particles formed at various concentrations of soluble polysaccharides were shown in Figure1. When the concentration of the pear polysaccharides was $1.25 \mathrm{mg} / \mathrm{mL}$, it was easy to find that the particles had two kinds of morphologies: spherical and sheaf-like. At the same time, some particles without the special morphology were also found. The diameter of the spheres was about 5-6 $\mu \mathrm{m}$, and the length of sheaf-like $\mathrm{CaCO}_{3}$ particles were about $20-25 \mu \mathrm{m}$ (Figure 1a.). However, with $2.5 \mathrm{mg} / \mathrm{mL}$ of pear polysaccharides, sheaf-like $\mathrm{CaCO}_{3}$ particles became the radiating cluster-like crystals. From the images of the radiating cluster-like crystals, the crystals made of flakes just like fish scales (Figure 1b.). Observing the SEM images of the products obtained under various concentrations of the apple polysaccharides, we found that spherical and sheaf-like $\mathrm{CaCO}_{3}$ particles were still obtained when $1.25 \mathrm{mg}$ / $\mathrm{mL}$ apple polysaccharides were presented in the system (Figure 1c.). Also, a further increase in the concentration of the apple polysaccharides to $2.5 \mathrm{mg} / \mathrm{mL}$ yielded more calcium carbonate crystals with a sheaf-like morphology only (Figure 1d.). Although, the diameter and the length of the as-formed particles were same as those formed in the pear polysaccharides solution, the particles were lack of anisotropic growth. The Crystals obtained in the water, in most cases, formed into ordered rhombohedral structures.

Such structures were generally composed of six (104) facets, a macroscopic embodiment of unit cells ${ }^{28}$. Therefore, it could be concluded that the soluble polysaccharides had a great influence on the morphology of $\mathrm{CaCO}_{3}$.

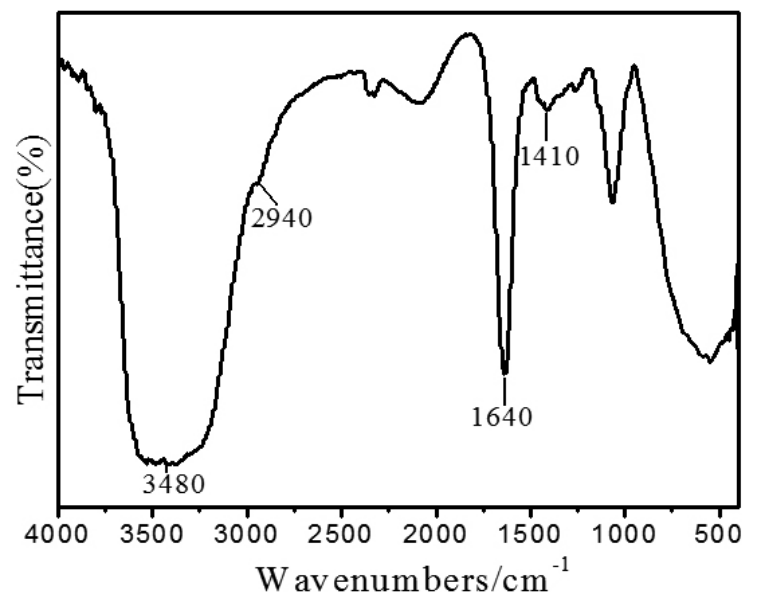

Figure 2. FT-IR spectra of apple polysaccharides.
There were four characteristic peaks (Figure 2), $3440 \mathrm{~cm}^{-1}, 2940 \mathrm{~cm}^{-1}$, $1640 \mathrm{~cm}^{-1}$ and $1410 \mathrm{~cm}^{-1}$ which could be attributed to $\mathrm{O}-\mathrm{H}$ stretching vibration, $\mathrm{C}-\mathrm{H}$ characteristic absorption peak, $\mathrm{C}=\mathrm{O}$ absorption peak and $\mathrm{C}-\mathrm{H}$ deviational vibration, respectively. From the above peaks, we could find that these are characteristic absorption peaks of apple polysaccharides.

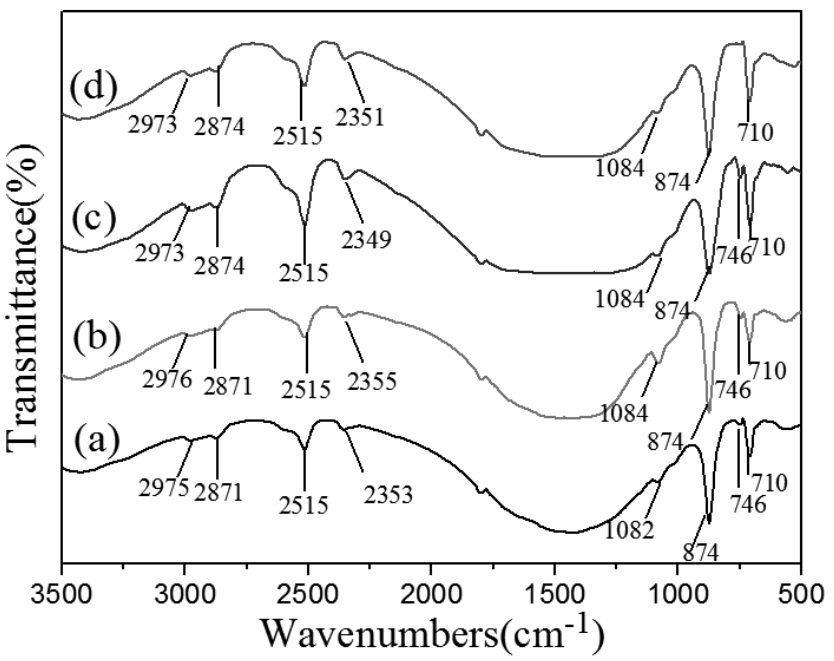

Figure 3. FTIR spectra of $\mathrm{CaCO}_{3}$ crystals obtained from system with AP and PP

(a) $\mathrm{PP}(1.25 \mathrm{mg} / \mathrm{mL})$, (b) $\mathrm{PP}(2.5 \mathrm{mg} / \mathrm{mL})$, (c) $\mathrm{AP}(1.25 \mathrm{mg} / \mathrm{mL})$ and (d) $\mathrm{AP}(2.5 \mathrm{mg} / \mathrm{mL})$.

Calcium carbonate samples prepared in different polysaccharides solutions with different concentrations named $\mathrm{a}, \mathrm{b}, \mathrm{c}$ and $\mathrm{d}$ were used to investigate crystal polymorph by means of powder XRD and FTIR analyses. As shown in Figure 3., three characteristic peaks at 874,710 , and $1088 \mathrm{~cm}^{-1}$, indicating the emergence of calcite in the whole samples (samples a,b,c,d), while the $746 \mathrm{~cm}^{-1}$ peak characteristic of vaterite was still observed except the crystal formed in $2.5 \mathrm{mg} / \mathrm{mL}$ apple polysaccharide solution (sample d). The FT-IR spectrum of calcite had a particularly interesting characteristic. It had a very intense sharp bands at 876 and $712 \mathrm{~cm}^{-1}$, which could be attributed to $\mathrm{n}_{3}$ (asymmetric $\mathrm{CO}$ stretching) mode, $\mathrm{n}_{2}\left(\mathrm{CO}_{3}\right.$ out-of-plane deformation) mode and $n_{4}$ (OCO bending in-plane deformation) mode vibrations ${ }^{29}$, respectively. The infrared spectra at $1084 \mathrm{~cm}^{-1}$ and $746 \mathrm{~cm}^{-1}$ were attributed to $\mathrm{n}_{1}$ (symmetric $\mathrm{CO}$ stretching) and $\mathrm{n}_{4}$ (in plane bending) mode of vaterite, respectively ${ }^{30}$.

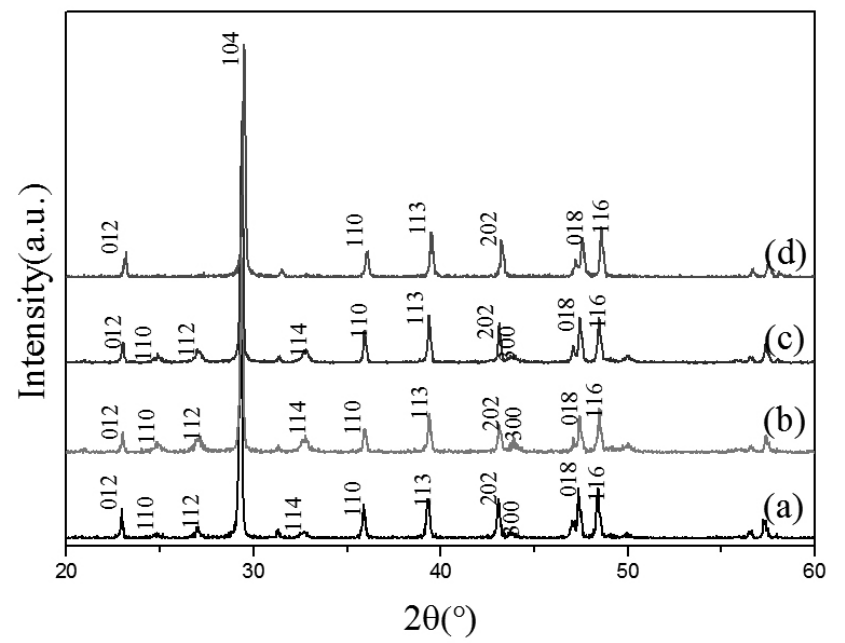

Figure 4. XRD patterns of crystals formed with different fruit extracts solutions

(a) $\mathrm{PP}(1.25 \mathrm{mg} / \mathrm{mL})$, (b) $\mathrm{PP}(2.5 \mathrm{mg} / \mathrm{mL})$, (c) $\mathrm{AP}(1.25 \mathrm{mg} / \mathrm{mL})$ and (d) $\mathrm{AP}(2.5 \mathrm{mg} / \mathrm{mL})$. 
According to JCPDS card, the corresponding XRD pattern of the $\mathrm{CaCO}_{3}$ crystals displays the following diffraction peaks (20), 20.89, 24.82, 27.01, $32.74,43.72,49.93$, and $55.90^{\circ}$, which are correlated to the $(h k l)$ indices $(004)$, (110), (112), (114), (300), (118), and (100) of vaterite (JCPDS card number 72-1616). While, the corresponding XRD pattern displays the following diffraction peaks $(2 \theta), 23.08,29.35,36.04,39.43,43.21,47.23$, and $48.40^{\circ}$, which are correlated to the (hkl) indices (012), (104), (110), (113), (202), (018), and (116), respectively, of calcite (JCPDS card number 72-1652). From Figure $4(a, b)$, we could confirm calcium carbonate formed in the pear extract solutions with a similar pattern. It suggested that the products consisted of vaterite and calcite phase. However Figure 4(c,d) suggested that crystals formed in the $1.25 \mathrm{mg} / \mathrm{mL}$ apple extract solutions still consisted of vaterite and calcite phase, in the $2.5 \mathrm{mg} / \mathrm{mL}$ apple extract solutions only most stable calcite. It was in agreement with the FT-IR results.

In addition, coexistence of calcite and vaterite instead of only vaterite in the products can be found from the corresponding XRD pattern (Figure 4.). If $\mathrm{I}_{\mathrm{C}}$ and $\mathrm{I}_{\mathrm{V}}$ are defined as the intensity of the characteristic diffraction peaks of calcite from (104) and vaterite from (110), the molar fraction of vaterite to calcite $\left(\mathrm{X}_{\mathrm{V}} / \mathrm{X}_{\mathrm{C}}\right)$ can be calculated by the equation (1).

$$
\frac{\mathrm{X}_{\mathrm{V}}}{\mathrm{X}_{\mathrm{C}}}=7.691 \frac{\mathrm{I}_{\mathrm{V}}}{\mathrm{I}_{\mathrm{C}}}
$$

In equation (1), $X_{C}$ and $X_{V}$ are the molar fractions of calcite and vaterite in a mixture, respectively. The intensities of the peaks of the (104) plane of calcite, and the (110) plane of vaterite are represented as $\mathrm{I}_{\mathrm{C}}{ }^{104}$, and $\mathrm{I}_{\mathrm{V}}{ }^{110}$, respectively. The content of vaterite in the mixture was about $8.79 \%$ (mol\%) (sample (a), which formed in $1.25 \mathrm{mg} / \mathrm{mL}$ PP solution), $32 \%$ (mol\%) (sample(b), which formed in $2.5 \mathrm{mg} / \mathrm{mL}$ PP solution) and $17.02 \%$ (mol\%) (sample (c), which formed in $1.25 \mathrm{mg} / \mathrm{mL}$ AP solution) by this equation.

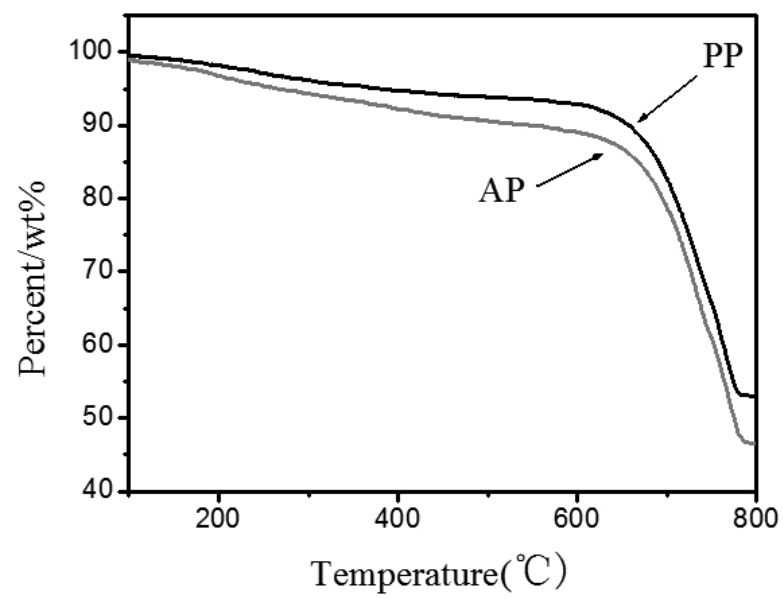

Figure 5. TGA curves of $\mathrm{CaCO}_{3}$ crystals obtained from a system with AP $(2.5 \mathrm{mg} / \mathrm{mL})$ and PP $(2.5 \mathrm{mg} / \mathrm{mL})$, respectively.

According to the previous literatures ${ }^{31-33}$, free and bound water molecules are fully lost at $<200^{\circ} \mathrm{C}$; the organic matrix will be decomposed between 200 and $350^{\circ} \mathrm{C}$, and combustion of organic residues occurs at temperatures between 350 and $550^{\circ} \mathrm{C}$. The lost appearing when above $600^{\circ} \mathrm{C}$ is due to the decomposition of $\mathrm{CaCO}_{3}$ into $\mathrm{CaO}$ and $\mathrm{CO}_{2}$. In this way, the TGA result determined the content ( $\mathrm{wt} \%$ ) of the organic matrix to be $7.62 \%$, and $5.31 \%$ in the $\mathrm{CaCO}_{3}$ samples formed at $2.5 \mathrm{mg} / \mathrm{mL}$ apple polysaccharides(AP) and $2.5 \mathrm{mg} / \mathrm{mL}$ pear polysaccharides(PP), respectively. (Figure 5 ).
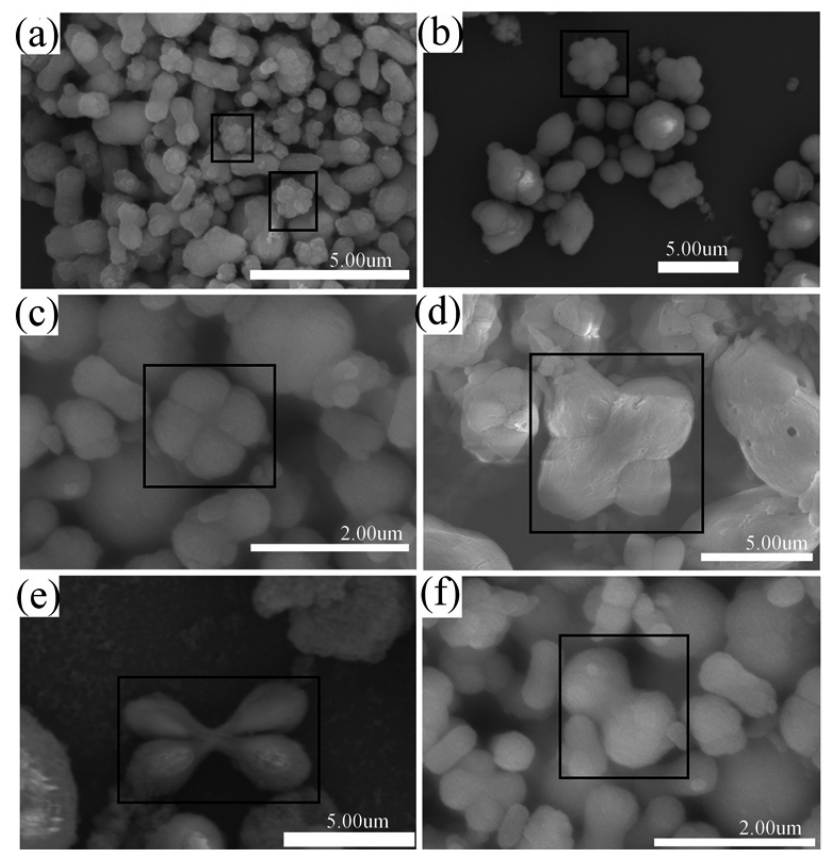

Figure 6. SEM images of the crystal acquired from $2.5 \mathrm{mg} / \mathrm{mL}$ AP solution at different reaction times: (a,b) $30 \mathrm{~min}$, (c) $1 \mathrm{~h}$, (d) $3 \mathrm{~h}$, (e) $5 \mathrm{~h}$, (f) $17 \mathrm{~h}$.

To gain a deeper understanding the crystallization processes of calcium carbonate that induced by polysaccharides, the samples were collected at different stages in the pear polysaccharides solution of $2.5 \mathrm{mg} / \mathrm{mL}$. Representative SEM snapshots of the products were serially showed in Figure 6. First and foremost, an overall trend from spherical and sheaf-like particles to more anisotropic superstructures was struck with the increase of the reaction time (see Figure 6a and 6b). At the same time, some particles with petal shaped appeared. With the prolonging of time, these petaloid particles gradually degraded from the initial multijaw into quadrifid petal like. Growing along with the warp and weft axis, these particles evolved into dumbbell with the CROSS type, and ultimately formed a stable bundle morphology (see Figure $6 \mathrm{c}, 6 \mathrm{~d}, 6 \mathrm{e}$ and $6 \mathrm{f})$.

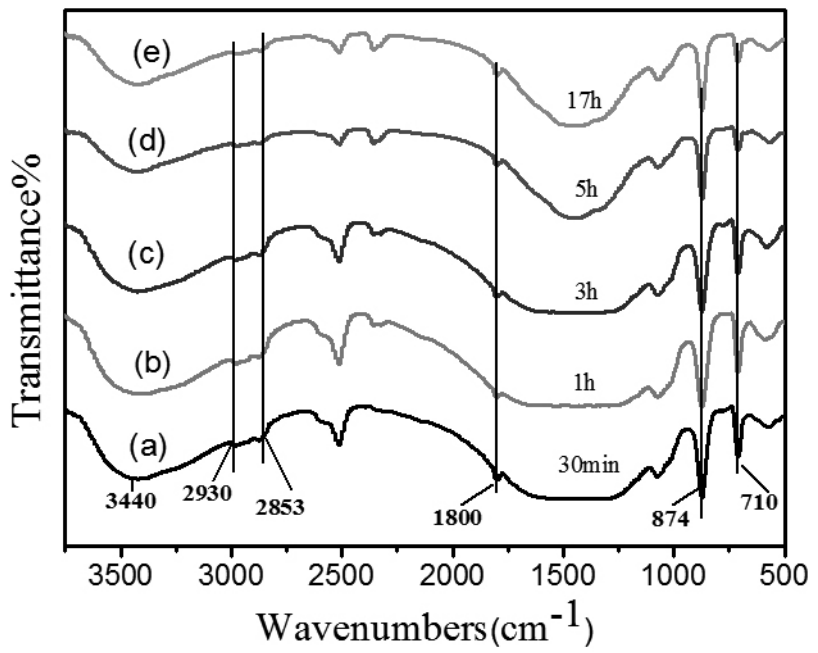

Figure 7. FT-IR spectra of the crystal acquired from $2.5 \mathrm{mg} / \mathrm{mL}$ AP solution at different reaction times:(a)30min,(b)1h,(c)3h,(d)5h,(e)17h.

The FT-IR spectra of the crystal/polysaccharide mixtures acquired from the $2.5 \mathrm{mg} / \mathrm{ml} \mathrm{AP}$ at the reaction times from $30 \mathrm{~min}$ to 17 hours were shown in Figure 7. The spectra of these samples were similar to each other and only slight differences can be observed in the shape and intensity of the bands. The FT-IR 
spectra, with the bands of out-of-plane deformation $\left(874 \mathrm{~cm}^{-1}\right)$ and in-plane deformation $\left(710 \mathrm{~cm}^{-1}\right)$ are attributed to calcite ${ }^{34}$.These results are consistent with the previous results in the Figure $3 \mathrm{c}$ and $\mathrm{d}$. The non-symmetrical and symmetrical stretching vibrations of $\mathrm{C}-\mathrm{H}\left(\mathrm{CH}_{2}\right)$ of AP are also evident at 2930 and $2853 \mathrm{~cm}^{-1} 31$, respectively. The broad peaks around $3440 \mathrm{~cm}^{-1}$ ascribed to the stretching vibration of $\mathrm{O}-\mathrm{H}$ from AP and water. Therefore, the FT-IR spectra had ascertained that the reaction products contain not only calcite but also AP molecules which was consistant with TGA analysis.

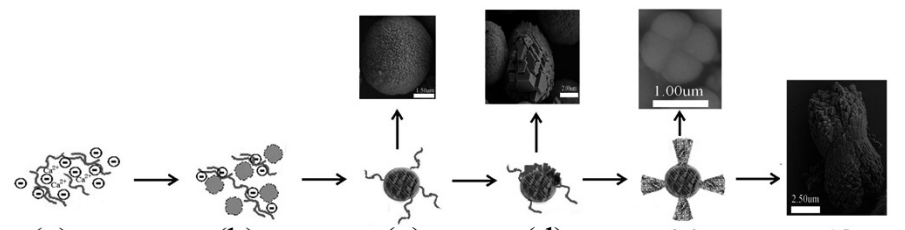

(a)

(b)

(c)

(d)

(e)

(f)

Figure 8. Scheme of the proposed formation mechanisms of $\mathrm{CaCO}_{3}$ particles and aggregates in the soluble polysaccharides solution.

From the results above, it suggests that the soluble polysaccharides extracted from pear or apple can influence the morphology of $\mathrm{CaCO}$ crystals. Calcite and the unstable vaterite come together while under high apple polysaccharides concentration only calcite appearing. According to the literatures described previously and the results presented above, we postulate a formation mechanism for the soluble polysaccharide-mediated superstructures (Figure 8). Because of hydroxyl groups (OH's) with negative charges, the polysaccharides would strongly interact with $\mathrm{Ca}^{2+}$ ions in solution, thus leading to local accumulations of $\mathrm{Ca}^{2+}$ ions. Crystallization starts within these local accumulations where the supersaturation is high. Because of the polysaccharides networks, the crystallization of $\mathrm{CaCO}_{3}$ is confined and leads to particles aggregate into a globular shape. The polycrystalline spherical cores act as the nucleation sites for the deposition of new short rhombohedral shaped calcium carbonate particles due to the instinct of precipitation of calcium carbonate. The rhombohedral shaped calcium carbonate particles further assemble into the spiciform shaped branches, developing into a straw bundle-like structure, due to Ostwaldripening and particle segregation arising from the polysaccharidesinduced lowering of surface energy and electrostatic repulsion. Thus, the crystallization process would go along the $(\mathrm{a} \rightarrow \mathrm{b} \rightarrow \mathrm{c} \rightarrow \mathrm{d} \rightarrow \mathrm{e} \rightarrow \mathrm{f})$ pathway.

\section{CONCLUSIONS}

A rapid, eco-friendly route has been successfully developed for preparing calcium carbonate with unusual morphologies using the soluble polysaccharides extracted from pear or apple. The polysaccharides serve as a soft template in the formation of straw bundles-like particles of calcium carbonate. The present green synthesis method involves using pear or apple extract in environmentally friendly universal solvent namely water, which would open a new route in the application of formed biomaterials. Future research using natural biomacromolecules for the synthesis of size specific particles would be an interesting area.

\section{ACKNOWLEDGMENTS}

This work is supported by the National Science Foundation of China (91022032, 21171001, 5097300121101054 and 21173001), the Important Project of Anhui Provincial Education Department (ZD2007004-1), Key Laboratory of Environment-friendly Polymer Materials of Anhui Province, Natural Science Foundation of the Education Department of Anhui Province (No. KJ2012B146).

\section{REFERENCES}

1. E.Baeuerlein,Handbook of Biomineralization: Biological Aspects and Structure Formation, Wiley-VCH, Weinheim,2007

2. M.S.Fernandez, Biomineralization: from Paleontology to Materials Science,Editorial Universitaria. Santiago, Chile,2007

3. S. Mann,Angew Chem. Int. Ed., 39,3392,(2000)

4. E.Dujardin, S.Mann, Adv. Mater.,14,775,(2002)

5. J.L. Arias, M.S.Fernandez,Chem. Rev.,108, 4475,(2008)

6. L.Chen, Y.H. Shen, A.J. Xie, Q.N.Cheng, J. Mater. Sci.,45,2938,(2010)

7. T. A. Ajith, K. K. Janardhanan, J.Clin. Biochem. Nutr.,40, 157,(2007)

8. S.Wasser, Appl. Microbiol. Biot.,60, 258,(2002)

9. M.Zhang,S.W.Cui, P. C. K. Cheung, Q. Wang, Trends Food Sci. Tech.,18, $4,(2007)$

10. A. Abolins-Krogis, Acta Zool.,39, 19,(1960)

11. B.X.Leng,F. G. Jiang,K. B. Lu,W.H. Ming, Z. Z. Shao, CrystEngComm,12, $730,(2010)$

12. Y.Y.Zhao,M.T. Carvajal,Y. Y. Won, M. T. Harris, Langmuir,23, $12489,(2007)$

13. H.Munro Natasha, M.McGrath Kathryn, Chem. Commun.,48, 4716,(2012)

14. W.Zhang,T.Liu,X.L.Hu,J. M. Gong, Rsc Adv.,2, 514,(2012)

15. X.D.Yang,G.Y.Xu, Y. J.Chen,W.P. Sui,Powder Technol.,215-216, $185,(2012)$

16. Y.D.Wu,C.Cheng, J. R. Yao, X. Chen, Z. Z. Shao,Langmuir,27, 2804,(2011)

17. R.Fried, Y.Mastai, J. Cryst. Growth,338, 147,(2012)

18. K. Kayano, K.Saruwatari,T.Kogure,Y.Shiraiwa, Mar. Biotechnol.,13, $83,(2011)$

19. C.Ercole, P.Cacchio, A. L.Botta, V.Centi, A.Lepidi, Microsc. Microanal.,13, 42,(2007)

20. Q.H.Zhao, Z.W. Mao, C.Y.Gao, J.C.Shen, Journal of Biomaterials Science-Polymer Edition, 17, 997,(2006)

21. L.Yang,X.Y.Zhang, Z.J.Liao,Y.M.Guo, Z.G. Hu, Y.Cao, J. Inorg. Biochem.,97, 377,(2003)

22. K.Jasminka, K.Damir, B.Ljerka, F.Giuseppe, J. Cryst. Growth,310, 4554,(2008)

23. F.Waltz, G.Wissmann, J.Lippke, A.M.Schneider, H.C. Schwarz, A.Feldhoff, S.Eiden, P.Behrens, Cryst. Growth Des.,12, 3066,(2012)

24. J.Shi,Z.Z.Zhang,W.Y.Qi,S. K.Cao, Int. J. Biol. Macromol.,50,747,(2012)

25. J. C.Liu,Y.X.Sun,L.Liu,C. L.Yu, Carbohyd. Polym.,889,1299,(2012)

26. Q.Han, Q. Y.Yu, J.Shi,C.Y.Xiong, Z. J.Ling, P. M.He, Carbohyd. Polym.,86,797,(2011)

27. A.Balaprasad,J. Nanosci. Nanotechnol.,11, 3997,(2011)

28. F.W.Yan,C.Y. Guo, X.H.Zhang, G.Q.Yuan,CrystEngComm,14, $1554,(2012)$

29. Y. F.Ma,Q. L.Feng, J.Solid State Chem.,184, 1008,(2011)

30. F. A.Andersen, L.Brecevic,Acta Chem. Scand.,45, 1018,(1991)

31. J. W.Xiao,S. H.Yang, CrystEngComm,12, 3296,(2010)

32. H.Cheng, L.P.Wang, Z.G.Lu,Nanotechnology, 19, 025706,(2008)

33. M.Faatz, F.Grohn, G.Wegner, Adv.Mater.,16, 996,(2004)

34. A.G.Xyla, P.G.Koutsoukos, J. Chem. Soc., Faraday Trans. 1,85 , $3165,(1989)$ 